\title{
Ignoring the Child and the Call for a Good Balance: Aspects of a Phenomenologically Based Theory of Teacher Actions
}

Kåre Fuglseth, University of Nordland, Bodø, Norway

Email: kare.fuglseth@uin.no

\begin{abstract}
This article explores the possibilities of articulating a theory of teacher actions in light of a critical or constitutive phenomenology of action. Through the use of a video analysis project, a case from a learning session is presented as a point of departure. The general question is whether constitutive phenomenology as a kind of reflective analysis may help to explore and understand the practical knowledge of a teacher in a classroom interacting with children. The situation is deliberately seen from the teacher's point of view, and seeks to demonstrate how the knowledge of teachers' actions in relation to a teaching subject, and in interaction with students' and children's calls, may be analysed. A general theory of teacher actions is formulated as a dynamic combination or balance of focal and global beliefs, values and practices, while different types of combinations of these phenomenologically described thetic "positionalities" are described to understand ignoring more generally. The ignoring of children in a classroom is further analysed and described according to the German Bildung tradition and the pedagogical paradox of formation. The article also discusses contributions and limitations of phenomenology in pedagogical research, and in relation to teacher student pedagogy in particular. ${ }^{i}$
\end{abstract}

\section{Video analysis and the study of actions}

In this paper, I shall theoretically elaborate on some different aspects of teachers' actions seen against a phenomenological analysis of action in general and some well-known nuts and bolts in pedagogical theory as seen in the European Bildung tradition. Above all, the article explores the possibilities of articulating a theory of teacher actions in light of Husserlian-based, critical and constitutive phenomenology of action. I am phenomenologically exploring a kind of action that at the outset seems to be a strange action for a teacher: the ignoring or negligence of children as a strategy. The ignoring of children's behaviour is a much-studied strategy in behavioural studies (Carr et al., 2002). However, the perspective in these studies is instrumental and naturalistic, while our phenomenological one is based on human research and is reflective in principle.

The research that inaugurated the study behind this article was not theoretical but practical. From 2009 to 2011, I was leading a research group that studied a counting, measuring and writing training programme in a kindergarten. We made video recordings of sessions with a group of six children (5-6 years old), with a teacher and an assistant 
who were not only responsible for the recording, but who were also normally present in the group. ii $^{\text {in }}$

In this study, we both observed the groups of children and teachers and partially participated in the room with the children to various degrees. Our main concern was to see if the programme could enhance learning by way of role-playing and games with the children. Together with a pre-school teacher, two of my colleagues in the group had developed the programme introducing some new principles for the activities that they hoped the children would enjoy, while improving the abilities of some basic competencies at the same time (Valle, Olvik, \& Orset, 2010). Nevertheless, our evaluation of the programme is not relevant for my discussion here (cf. Fuglseth, Orset, \& Valle, 2011). However, the general approach towards social interaction and the insights we gained about the teacher's perspective seem highly relevant for the development of a more general and phenomenologically oriented theory of teacher actions. The approach seems necessary for achieving an understanding of any "call”, and I shall demonstrate how this is related to the fundamental problem of the pedagogical paradox of formation.

In the European, and particularly the German tradition of Bildung or formation, the relational aspect of teaching is often described as a dilemma or paradox (cf. Benner, 2008; 2010). The theory proposes that it is possible to form other people, the so-called "Bildsamkeit" (the possibility to form someone), while simultaneously suggesting that students or every human being must always form themselves, the "autopoiesis". The claim in this Bildung tradition is that the former (the objective aspect as seen from the learner) is not possible without the latter (the subjective aspect) and vice-versa. For instance, if we want to have independent and democratic-minded adult citizens, some type of non-democratic means is necessary. A liberal society is never completely liberal; thus, there is a necessity (at least to some extent for the child) to meet unknown aspects of a common tradition in any society, such as ideas from former researchers and thinkers. This approach is in high accordance with the understanding of the relational way of understanding pedagogy seen in the Mollenhauer reception (cf. Friesen \& Sævi, 2010).

In our video analyses we focused on the direct meeting between teacher and children, and we attempted to describe, understand and explain the interaction taking place in the situation. For the purpose of analysis we turned to what is now called videography, a complete methodology based on interpretive or hermeneutic sociology that is phenomenologically informed (Knoblauch, Schnettler, Raab, \& Soeffner, 2006). Videography combines a sequential analysis based on conversation analysis (i.e. with a special focus on meaning turns), as well as ethnography, in order to grasp both the situational (synchronic) and non-situational (diachronic) aspects of the interaction at the same time. The approach also demands an interpretive collective procedure well-known from phenomenological and hermeneutic approaches, in which it is seen as essential to articulate as many interpretations of the situation as possible to help facilitate further discussion in the research group. On a general level, one might ask how it comes to be that the participants understand the situation as they seem to do, and what type of communicative resources are presented by the participants as revealed by the video. Video recordings are easily managed, and are a particularly rich way to carry out an observation. Hence, we ask what it is that constitutes meaning and meaningful communication in the situation for the participant children and their teacher? 


\section{Fuglseth}

After the first analysis of the video recording by the researchers, the participant teachers were invited to help with the interpretation. The present reflection was developed from a specific studied instance in which our group made a disturbing observation. We saw a teacher who clearly overlooked one of the children. Seen against this discovery, I have chosen to focus this analysis on the situation as seen from the teacher's point of view. Naturally, the child's lived experience is important, but due to space limitations, it will not be elaborated on here. Before any such individually based description of the lived experience, one must first clarify the phenomenon in question (ignoring) from a critical and general perspective. Only some aspects of ignoring can be discussed here, so the next logical step is to study in more detail the actual richness in the experience by both the child and the teacher.

\section{The call of the ignored girl at the kindergarten}

At the teaching session under study, the children were gathered in a semi-circle, with the teacher on her knees in front explaining and discussing what worms look like. The teacher had even brought in a small living worm in a bucket to demonstrate how worms may stretch and shrink their bodies (for the purpose of introducing the students to the differences between long and short, etc.). We were astonished to discover that the teacher let every child participate in the conversation with one exception. One of the girls was refused permission to say anything, although she eagerly raised her hand every time the teacher asked a question or called for an opinion. "Wait", the teacher said to her, but she was never given the chance to speak, and often mumbled barely audibly to herself the answer that she wanted to present. The girl was openly ignored, which does not seem to be a good response to the call made by the child. However, the case did not turn out to be as easy to grasp after our discussion with the teacher, and after having studied the case on tape together with her.

The teacher explained to us that what she did was done with a clear and specific purpose: The ignored girl had actually already been favoured, as she had been allowed to go with the teacher outside to find the worm. All of the different aspects of the teaching session had been discussed at length with this child, so the teacher then decided to allow the other children in the group to speak before the ignored girl presented all the answers for them. The learning effect and social training would then have been minimal for the other children since they would not have been given the opportunity to actively engage in the thinking and articulations behind their questions and answers.

The explanation seemed rational to our group of researchers, since being teachers ourselves, we have often been in a similar situation. For example, in presentations of a subject to a large group of student teachers, one might rarely let everyone speak. In a similar way, it was simply not possible to treat all the children as individuals during this kindergarten lesson, lasting only 15 minutes. Nevertheless, it was this complete negligence that compelled us and made us wonder.

The case in question is therefore a more general question about the approach of teachers toward children in groups. This is an important ability that student teachers need to learn in order to teach in schools, and is one of the most common situations for teachers the world over. At the same time, both collectively and individually, handling children is a matter of great concern that is essential for every type of learning result, and 
perhaps even more so in an individually dominated Western culture. In practice, experienced teachers often do this intuitively. Some seem to master it initially, while others do not, so one may wonder if it is possible to create a working theory that would help develop this ability.

In order to fully understand this ability from the teacher's point of view, a study of the phenomenon of ignoring demands further inspection. It is definitely not the only way, but one approach is certainly to attempt to phenomenologically describe ignoring. By phenomenology, I mean a reflective analysis and constitutive phenomenology (Embree, 2003; 2007), as well as the specific branch developed on the basis of social- or intersubjective Husserlian philosophy of Alfred Schütz (Schütz \& Luckmann, 1972; 1979; 1984; Luckmann, 1992). How can ignoring be described phenomenologically and then in the next instant, how can ignoring in this educational context be reflectively analysed as a pedagogical call?

\section{A phenomenological analysis of ignoring in general}

To study something phenomenologically is to study both the noetic and noematic aspects of the phenomenon (i.e. we need to look at both the ignoring itself and the things-as-met, or ignored-as-ignored). Here, a "thing" is to be taken in the broadest possible way; it includes, e.g. objects, thoughts, persons and actions. A general phenomenological theory of action is a natural place to start analysing a phenomenon such as ignoring or neglecting, and there are several theories of social actions in phenomenological literature, thus we do not need to start from point-zero. While studying previously articulated theory we may evaluate, criticise, reject or accept, thereby developing these further in different thematic fields.

In describing the basic elements of any human consciousness or intentionality that deserves much more attention than it has received until now, including in phenomenological pedagogy, Lester Embree builds on a genuine Husserlian approach in his book on reflective analysis (2007). Action or "willing", practice or the volitional component of intentionality are one of the three main thetic components (positionalities) described by Husserl. Referring to his teacher, Dorion Cairns (a direct student of Husserl and the first American phenomenologist), Embree prefers the word intentiveness, or encountering instead of intentionality, to differ it from intentionality as a description of actions with a specific purpose. In addition to the volitional components, we also find two other thetic components: believing/beliefs (i.e. a theoretical, cognitive component) and valuing/values, including feelings, moods, and so forth (i.e. a valuational, emotional and axiotic component). In any call such as those discussed here, all these components are present as tacit knowledge.

Embree (2007, cf. 2012) describes how these components or positionalities may be combined and turned towards themselves to include a thick description of actions, whether social or non-social. Thus, we have mostly theoretical or cognitive actions (e.g. theories about theories, values and actions), valuational actions (e.g. judgements of actions, theories and values), as well as practical actions. For example, a practical action could be a routine-based action or habit that we engage in without being theoretical about it, and without taking an active stand either for or against it. These components also have three modalities each: they are positive, neutral and negative in combinations. There is a 


\section{Fuglseth}

clear theoretical advantage to abstracting the valuational modalities and the volitional and cognitive ones while studying ignoring. Although in actual life these actions and the modalities within them are always intertwined, one or the other may dominate in one particular action and situation.

Because teachers mostly deal with groups, one should be particularly aware of the difference between treating collectives and individuals. In this context, it is also necessary to discern internal from external values; what is good for me as I look upon a given matter may be different from what another person would think about it. One example of this would be when a doctor tells a patient to exercise and the patient only rather unwillingly follows the doctor's order. We may further differentiate between actions willed to be "on purpose" as opposed to "by accident", and engaged in as opposed to the habitual and traditional (collective habits) or "under compulsion", both in voluntary and involuntary intentiveness (Embree, 2007:101). Likewise, ignoring may be just a bad habit or a necessary ability on the part of a teacher dealing with children in groups.

The advantage of abstracting the theoretical and valuational components referred to above is evident when it comes to the study of ignoring. Ignoring someone would perhaps not normally be seen as a positive action, though from the point of view of a doctor, teacher or parent this is not that evident. Challenging, admonishing, demanding and so forth, often have these same negative connotations, but avoiding them completely may also be looked upon as a disservice to the child. Doing homework or an exam at school may be valued differently, both internally and externally. Reproaching a child may be seen as an advantage for the child, even though the child does not like it. Likewise, ignoring also has external and internal values.

Seen as more isolated or abstracted without evaluations, ignoring in itself is neither destructive nor constructive, that is, one does not tear down or build up, but instead describes a kind of aboulia, a non-action. One refrains from doing something, one lets it be as it is. I shall therefore argue that from this abstract practical point of view ignoring is a neutral action, which in turn may be regarded with a negative, neutral or positive view or value, but that is something else, as one may like, dislike or not care about ignoring. In addition, these values are always internal or external. I may look upon ignoring as either being good for myself, good for someone else, or as being bad for me or bad for someone else. Thus, what is good for the group may be bad for the individual.

Another principal difference of actions that turned out to be essential in our analysis of this situation was the division into those actions that are globally directed (in the long run) and those that are focally directed (actualised, present now). Interestingly, we find a focal willingness or action in one modality (negative) together with a global willingness in another modality (positive). Nonetheless, both a global and focal willingness can simultaneously occur in opposite modalities (Embree, 2007:105). We may have a negative action in front, a "destruction" that is seen as a positive external value only against the overall positive constructive effects in the background, which is similar to the carpenter who tears down a wall in order to improve or rebuild a house (Embree, 2007).

This way of thinking is similar to the idea behind role modelling: "I'll show you what you are not supposed to do." A disservice is another example of an action with opposite focal and global modalities and values. It seems like a favour at first, but turns out to not be a favour later, as it is an action that has a focal or present positive value, both 
externally and internally. However, it turns out to have unexpected fatal consequences where the global aspects are concerned, and is also negatively regarded internally and externally in the long run. The term "opposite modalities" is used when actions are focally valued in one way and globally in an opposite way, e.g. focally negative or neutral, while globally positive.

\section{Ignoring in an educational situation}

Ignoring or negligence is an action that from the teacher's point of view may also be seen as a neutral valuational modality (i.e. as being externally valued). From the point of view of the ignored girl (i.e. internally), the value component was in fact negative. Obviously she did not like to be ignored, though at the same time she did not seem to be too disappointed either. The teacher defended her actions when asked about it, and was actually very clear about it in our interpretation seminar. Thus, the component involved here is a positively external value (both in the action and afterwards).

For the research group, it was essential to understand how the teacher came to positively value the ignoring. In (constitutive) phenomenological language, the answer seems to be that it was seen by the teacher as a focal neutral modality against the global positive modality of the action, independently of whether this is correct or not by our external evaluations of the action. Hence, there is a structure involved in this ignoring; there is a global positive end with focal neutral means.

In fact, opposite modalities in teaching is a common theme in pedagogical philosophy, which is exactly the structure of what European theorists of education (Bildung, formation) call the "pedagogical paradox" (see above). This means that a building or formation needs an objective or external drive, as well as an internal one at the same time. Luhmann (2002) argues that the dilemma only seems to be since the values involved relate to two different systems: teaching and learning (i.e. being viewed externally or internally). From the practitioner's subjective point of view, however, there is clearly a dilemma present in all these situations since opposite values are clearly involved. It is better to explain the pedagogical dilemma as a result of a situation in which what is globally intended in the background of the whole is different to the focal objects in the foreground. Putting the appropriate "things" (subjects, actions, words, objects, values, deeds, etc.) in front in any situation in which children learn is in this way part of the essential knowledge of experienced and expert teachers.

Telling people what to do may be looked upon as a positive action that is focally negatively valued since the teacher wants the child to find out by him/herself what to do, but it often turns out that one cannot avoid instructions altogether. There is a global benefit involved in making someone learn that also motivates the focal action by the teacher, which is why the evaluation in our research group of ignoring turned out not to be as straightforward as we initially thought. Removing the phenomenological brackets, we now see that the actual ignoring in the classroom was not necessarily negative. The teacher ignored the previously favoured girl for a global benefit, perhaps more for the benefit of the group and for each of the other children than for the benefit of girl in question. Considering the fact that the child in question was actually well attended to by the teacher, the child was not genuinely ignored. Ignoring in one particular situation may 
therefore be looked upon as having a positive value if there is a global valuational and positive perspective added.

\section{The good balance: A focal-global theory of teaching}

Against this background of the ignoring teacher in the kindergarten, we may also say something about teacher actions in general: A good teacher seems always able to act both focally and globally in the right way in meeting with children or students. Within the overall call, there is a call for a good balance of these features. The main key to understanding the evaluations of the situation as seen from the teacher's point of view, is not only this balance, but also the claim that the balance cannot be planned in advance, at least not in toto. In this way, my claim is opposite to any rational thought or instrumentalism. The diachronic development of the situation and understanding of it in hermeneutic circles tells a very complex story that is impossible to plan exactly. What can be planned are only certain anonymous types of results, and also these typical results have to be reconsidered during the action.

The "right way" of handling this is of course a matter for further discussion, although there is not enough room for that discussion here. My interest is to explore the possible general structures of a good balance. In any case, a teacher can never really operate with a negative global willingness vis-à-vis the students, as he or she cannot want to tear down globally, so to say, only locally or focally. Additionally, there are obviously objective criteria for the curriculum and the expectations of the parents, as well as society in general, regarding the end situations for teaching that must be considered. In one way or another the subject of learning itself is also present in its own structure, or sometimes in an alleged one. There are several other factors involved in real life that help to form or not form a human being, or for that matter even whole cultures or societies. Nevertheless, a reflection of the relationship of means and ends and their different modalities seems to be a type of imminent pattern of teachers' actions. Thus, such a reflective approach to it is necessary if we do not want to be caught up in an instrumental way of thinking. Furthermore, what shall the teacher do in the encounter with a specific child and the teaching subject and aim, and what kinds of "methods" are appropriate? A teacher can never avoid these kinds of considerations.

In relation to the pedagogical dilemma of formation, a focal-global theory of teaching clearly demonstrates both core ingredients of the teacher-student interaction with learning aims, as well as some of its problematic aspects in practice. In particular for new teachers, this kind of evaluation in action is difficult, if possible at all, especially when one has to improvise, since they often have few patterns of previous judgements and practices to rely on. In most cases, teachers can trust a scheme in which modalities are congruent, that is, a positive action (not neutral or negative) is positively externally valued, both focally and globally, by parents and others. However, one may never be too sure. Neutral and negative actions (ignoring and de-learning) may also be necessary for a global, positive value to be achieved individually and collectively. The building of attitudes related to commonly accepted values such as seen in democracy, citizenship, tolerance, kindness and so forth is not necessarily straightforward, but can include opposing modalities. 
In this way, the good balancing of focal and global aspects of action may also be linked to similar aspects of the two other positionalities presented above: believing and valuing, and beliefs and values (e.g. when these are teaching subjects). Teaching subjects always have global categories in addition to their focal ones, a claim that was introduced as a basis for teaching by the German scholar Wolfgang Klafki, and the Klafkian approach also includes valuational components in regard to the subjects (the teacher's evaluation of theories or beliefs) and the children in relation to formation (Bildung), the so-called categorical formative principle (Klafki, 1963). The theory of balancing may further be related to the phenomenological base theory of action patterns as elaborated by Schütz and Luckmann (1972), who explicated how the stock of knowledge (knowledge as included in beliefs, values and actions) or our foreknowledge is structured like all lifeworld knowledge, and which is sometimes formed to a fixed pattern or schemata of different degrees of firmness. For the teacher in our case, the ignored child represented one category of children with a call that was immediately answered in a specific way. The teacher referred to above clearly thought she had found this balance.

Our research group understood her arguments, but perhaps thought that her judgement was too hasty and she should not have completely refused the girl a turn to speak. Seen from the teacher's point of view, one could say that individuals in a learning group may benefit from patterned collective actions, even when it includes this kind of negligence. However, even if we accept the solutions of a teacher (including our own actions as teachers) we can never see them as a global rule or pattern, and it could be that the case discussed here is one of few examples of a justified ignoring in these teaching situations. A teacher may sometimes act in relation to the collective and at other times more individually, but finding the proper focal and global balance in a situation is not easily theorised beforehand. In relation to teacher education, these challenging dilemmas should naturally be highlighted for the global benefit of the student teachers and their future students.

\section{Limitations of the focal-global teaching theory}

I have investigated different appropriations of a general phenomenological theory of action in relation to the concrete actions of a teacher in an interaction with children. There is a common structure in the ignoring and in the call, and I have attempted to demonstrate how constitutive phenomenology may help to see parts of this structure in all its richness. A reflective analysis reveals what is involved and at stake, and against this background, we may articulate both a theory of ignoring and of teachers' actions in general and in so doing, formulate at least aspects of a theory of justified teaching. This also shows some possible theoretical contributions from Husserlian constitutive phenomenology generally, which is an approach that is yet not very well developed. The analysis also reveals some of its limitations: These considerations can only be a starting point for further empirical studies and for the theorising of teachers' actions. The empirical efforts start where the phenomenological studies end (cf. Raab, Pfadenhauer, Stegmaier, Dreher, \& Schnettler, 2008).

Generally speaking, much of the theory presented here may also be informative for other types of leadership and not only for the leadership of learning in schools. One particularity of teaching as opposed to the work of a carpenter, and in fact most other 
professions in the modern world, is that results or consequences of the actions are not immediately apparent. Most of the consequences of a teacher's action are only indirectly observed and sometimes never seen directly.

The main objection to such a theory of action in relation to teachers is that it is too general to be of any practical use. A general theory that fits every challenge obviously has a low justifying power. Nonetheless, the formulating of the theory is only the starting point for further concrete actions in relation to school or teaching situations. For the appropriation of the theory to teaching situations, we need to study these in a more broad and detailed way. What is a good answer to the call of the child is not easily known beforehand, but needs a situational consideration and a further collective and long-term consideration of the consequences. Independently of our evaluations of it in the described case, the ignoring clearly exhibits the difficulties involved. In our case, we found out that at no point was the ignored child genuinely ignored, nor was her benefit subsumed to that of the group, although she was attended to differently. The pedagogical call is clearly challenged by this phenomenologically based theory of global and focal modalities in action. Basically, this is the structure of any call that cannot be unthematised, which may in the next instance provide a nuanced understanding of the phenomenon of ignoring in the classroom that may be of great benefit to current and future teachers.

\footnotetext{
i The article is based on a paper presented at the International Human Science Research Conference (http://www.open.ac.uk/socialsciences/ihsrc2011/) in Oxford in July 2011. It has also been discussed in the phenomenological research group at our university.

ii In total, we had approximately 12 hours of recording. All teachers and parents had given their written consent and the children were willing to participate. The project has been terminated and all digital recordings deleted. The investigation was approved by the Data Protection Official for Research http://www.nsd.uib.no/personvern/.
}

\section{References}

Benner, D. (2008). Bildungstheorie und Bildungsforschung. Grundlagenreflexionen und Anwendungsfelder. Paderborn: Ferdinand Schöningh.

Benner, D. (2010). Allgemeine Pädagogik. Eine systematisch-problemgeshichtliche Einführung in die Grundstruktur pädagogischen Denkens und Handelns. Weinheim: Juventa.

Carr, E.G., Dunlap, G., Horner, R.H., Koegel, R.L., Turnbull, A., Sailor, W., . . Fox, L. (2002). Journal of Positive Behavior Interventions, 4(1), 4-16.

Embree, L. (2003). Reflective analysis in and of social psychology. A model for interdisciplinary phenomenology.In C.-F. Cheung, I. Chvatik, I. Copoeru, L. Embree, J. Iribarne \& H. R. Sepp (Eds.), Essays in celebration of the founding of the organization of phenomenological organizations. Available from www.o-p-o.net. Downloaded January $15^{\text {th }}, 2012$. 
Embree, L. (2012). Animism, adumbration, willing, and wisdom. Studies in the Phenomenology of Dorion Cairns. Bucharest: Zeta Books.

Embree, L. (2007). Reflective analysis. A first introduction into phenomenological investigation. Bucharest: Zeta Books.

Friesen, N., \& Sævi, T. (2010). Reviving forgotten connections in North American teacher education. Klaus Mollenhauer and the pedagogical relation. Journal of Curriculum Studies, 1-25.

Fuglseth, K., Orseth, A. K., \& Valle, A. M. (2011). Samhandlingstypar i praktisk kunnskap. Videoanalyse av Tallsprell og Språksprell i praksis. In In T. Løkensgard Hoel, T. M. Guldal, C. F. D. Dons, S. Sagberg, T. Solhaug \& K. Wæge (Eds.), Fou i praksis 2010 (pp. 123-132). Trondheim: Tapir. (ET: Types of cooperative acts in professional knowledge).

Klafki, W. (1963). Studien zur Bildungstheorie und Didaktik. Weinheim: Beltz.

Knoblauch, H., Schnettler, B., Raab, J., \& Soeffner, H.-G. (2006). Video analysis. Methodology and methods. Qualitative audiovisual data analysis in sociology Frankfurt am Main: Peter Lang.

Luhmann, N. (2002). Das Erziehungssystem der Gesellschaft. Frankfurt am Main: Suhrkamp.

Luckmann, T. (1992). Theorie des sozialen Handelns. Berlin: de Gruyter.

Raab, J., Pfadenhauer, M., Stegmaier, P., Dreher, J., \& Schnettler, B. (Eds.). (2008). Phänomenologie und Soziologie. Theoretische Positionen, aktuelle Problemfelder und emprische Untersuchungen. Wiesbaden: Verlag für Sozialwissenschaften.

Schütz, A., \& Luckmann, T. (1972). The structures of the life-world; 1-2. Evanston, Northwestern University Press.

Schütz, A., \& Luckmann, T. (1979). Strukturen der Lebenswelt; 1, Frankfurt am Main: Suhrkamp.

Schütz, A., \& Luckmann, T. (1984). Strukturen der Lebenswelt; 2, Frankfurt am Main: Suhrkamp.

Valle, A. M., Olvik, L., \& Orset, A. K. (2010). Tall - og språksprell i barnehagen. Oslo: Gyldendal akademisk. (ET: “Tall - og språksprell” - The learning of numbers and letters in the kindergarden). 